\title{
UMIEFsp II SIMPÓSIO NACIONAL

\section{Adolescência e maternidade: intervenções no processo gestacional: pré-natal - parto - puerpério em uma maternidade pública estadual da cidade de São Paulo}

\author{
Coríntio Mariani Neto \\ Hospital Maternidade Leonor Mendes de Barros \\ Claudete Ganéo Chuba \\ E-mail: chubacgc@gmail.com \\ Cristina Helena Rama \\ Fernanda Maria Vaz de Lima Codorniz \\ E-mail: fernandamaria2102@gmail.com \\ Márcia Toyoko Tanaka \\ Marilza Luchesi de Mello Teixeira
}

Como citar:

NETO, Coríntio Mariani et al. Adolescência e maternidade: intervenções no processo gestacional: pré-natal

- parto - puerpério em uma maternidade pública estadual da cidade de São Paulo. In: II SIMPÓSIO NACIONAL SOBRE ADOLESCÊNCIA: VULNERABILIDADE, PROTAGONISMOS E DESAFIOS, 2. 2016, São Paulo. Anais...[S.I]: 2016. p. 60-61.

DOI: http://dx.doi.org/10.22388/2525-5894.2016.040

Introdução: a complexidade da prática clínica que envolve adolescentes grávidas tem nos sensibilizado cada vez mais em nossa rotina hospitalar, diante da dupla mãe-bebê.

É impactante constatar a repetição das carências afetivas, educacionais, sociais e culturais, que são transmitidas de uma geração a outra, podendo ocasionar uma nova gravidez, sem fazer parte de um projeto de vida consciente, deliberado e com apoio familiar.

O turbilhão da adolescência atravessada pela gravidez impulsiona de maneira significativa a elaboração de inúmeras perdas, com as quais tem que se confrontar, havendo um corte radical no desenvolvimento. A possibilidade de vivenciar este momento de forma consciente colocando-se como protagonista de sua história, faz toda a diferença.

O nosso trabalho visa o fortalecimento dos vínculos mãe - pai - bebê - família, desde sua entrada no prénatal com Grupos de Incentivo ao Aleitamento Materno, atendimento psicológico nas enfermarias quando do nascimento do bebê até a saída do hospital, dando continuidade no Ambulatório.

Diante da complexidade que se encontra a adolescência, estamos lidando com um puerpério que necessita de um olhar mais abrangente na atenção e cuidados individualizados, onde o trabalho em equipe é de suma importância para um direcionamento adequado às demandas. As adolescentes atendidas são encaminhadas ao Ambulatório de Planejamento Familiar, onde a Equipe Médica as orienta sobre os diferentes métodos contraceptivos, focando nos métodos reversíveis de longa duração. 
O cuidar diferenciado dessa adolescente na área da saúde, faz parte de articulações necessárias para o fortalecimento da rede. As redes de contato são acionadas: parceiro, familiares, amigos e redes de atendimentos (RAPS - Rede de Atenção Psicossocial).

Objetivo: assegurar às adolescentes oportunidades de escolhas mais conscientes e maior adesão durante o processo gestacional às ações de Planejamento Familiar, numa maternidade pública da cidade de São Paulo.

Metodologia: este trabalho foi iniciado em maio/2013, com a Equipe de Psicologia através de abordagem às puérperas adolescentes internadas nas enfermarias do setor Alojamento Conjunto. Na alta hospitalar já é agendada a data para o seu retorno no Ambulatório do Planejamento Familiar, pela equipe Psicologia. Na consulta, recebem as informações da equipe sobre os diferentes métodos contraceptivos para fazer a sua escolha. É prática da Equipe Médica não perder a oportunidade de iniciar a anticoncepção imediata já na primeira consulta, focando nos métodos reversíveis de longa duração como o DIU com cobre por serem mais eficazes e práticos em seu uso.

Paralelamente há o acompanhamento da Psicologia relacionado às questões subjetivas deste período, contribuindo para uma maior adesão ao Planejamento Familiar.

Resultados: após a sistematização deste trabalho houve maior adesão das adolescentes às ações de Planejamento Familiar. Especificamente nas inserções de DIU com cobre, a proporção de uso deste método contraceptivo de longa duração (até 10 anos) por adolescentes (14-19 anos) aumentou consideravelmente. Elevando-se de 2,7\% (5/186) para 15,6\% (33/212) do total de DIUs inseridos, respectivamente, no período anterior (2010 a abril/2013) e após o início deste trabalho (maio/2013 a agosto/2016).

Conclusão: um atendimento diferenciado com escuta ampliada possibilita uma maior adesão ao planejamento familiar. Possivelmente a adesão da adolescente em serviços sem acolhimento adequado, dificulta esse processo. O encaminhamento para o Planejamento Familiar por si só não garante que a adolescente faça a adesão. Porém um atendimento diferenciado, englobando família, companheiro, amigos e com uma escuta ampliada das demandas de cada caso, fortalece o vínculo com a instituição, ocasionando uma conscientização da paciente quanto às oportunidades de escolhas mais conscientes para que as futuras gerações sejam fortalecidas com bases mais sólidas e planejadas.

Palavras-chaves: Adolescência. Planejamento familiar. Acolhimento. Contracepção de longa duração. DIU com cobre. 